\title{
Synthesis of $\mathrm{Ga}_{2} \mathrm{O}_{3} / \mathrm{HZSM}-5 @$ cubic ordered mesoporous $\mathrm{SiO}_{2}$ with template Pluronic F127 to improve its catalytic performance in the aromatization of methanol
}

\author{
Shuang $\mathrm{Chu}^{1} \cdot \mathrm{Xingcui} \mathrm{Guo}^{2} \cdot \mathrm{Jian}^{\mathrm{Li}^{1}} \cdot \mathrm{Jin} \mathrm{Bai}^{1} \cdot{\mathrm{Xindong} \mathrm{Mu}^{2} \cdot \mathrm{Li} \text {-na Yang }}^{1}$
}

Published online: 26 December 2016

(C) Springer Science+Business Media New York 2016

\begin{abstract}
A composite HZSM-5@cubic ordered mesoporous $\mathrm{SiO}_{2}$ (HZ@COMS) was synthesized by an acidic sol-gel coating method with template Pluronic F127.HZ@COMS and Ga loading HZ@COMS (Ga/HZ@ COMS) were applied in methanol to aromatics (MTA). The existence of the silica shell reduces the acid amount and acidity of HZSM-5, which decreases in the formation of coke on the catalyst. At the same time, such silica shell with 3D hierarchical and cubic ordered mesopores improves the diffusion of seeds and coke precursor. As a result, the catalytic performance of HZSM-5 was improved effectively with the introduction of silica shell in such structure. Making a comparison with HZSM-5, the longevity of HZ@COMS increased from 10 to $42 \mathrm{~h}$ and the selectivity of BTX increased from 44 to $49 \%$. After Ga's loading, the cubic ordered mesopore offered a nanoscale reactor in the reformation of $\mathrm{C}_{9}+$ hydrocarbons, which further improves the longevity of catalyst (54 h) and the selectivity of BTX (50\%). Ga/HZ@COMS presents good ability in the regeneration ability in MTA.
\end{abstract}

Keywords Core-shell - Cubic ordered mesopore . HZSM-5 · F127 · MTA

Li-na Yang

yanglnzg@163.com

1 College of Chemistry, Chemical Engineering and Environmental Engineering, Liaoning Shihua University, Fushun 113001, People's Republic of China

2 Key Laboratory of Bio-based, Qingdao Institute of Bioenergy and Bioprocess Technology, Chinese Academy of Sciences, Qingdao 266101, People's Republic of China

\section{Introduction}

Generally, benzene (B), toluene (T) and xylene (X) are known as important chemical raw materials, they are often synthesized by the catalytic reforming of naphtha [1]. At the same time, methanol, as a common and cheap organic material, to be an another important raw material to the production of BTX, due to the continuously price rising of the oil price and increasing consumption of aromatics [2]. HZSM-5 is often selected and regarded as a promising catalyst in methanol to aromatics (MTA) for its acidity, high thermal stability, large surface area and adjustable pore size comparable to the molecular dimension of BTX [3]. However, the conventional ZSM-5 is easy to be deactivated, for the deposition of large molecular in the zeolite's pores [4]. On the basis of the existing literature, the coke precursor with the size beyond the micropore size formed on the external acid sites [4]. In order to improve the diffusion of coke precursor and the adjustment of the external acid sites, the construction of mesopores with acidic or basic treatment has been tried [5-7]. Unfortunately, acidic or basic treatment destructs the framework of ZSM-5, the destruction of framework can lead to crystalline defects, which accelerates the dealumination under the condition of hydrothermal, thereby the thermal stability and the catalytic shape selectivity of the parent catalyst decrease remarkably [8].

The construction of core shell structure with a simple silicon deposition has been done, the external $\mathrm{Al}$ of HZSM- 5 can be pacified and there are no transport restrictions at all for large molecules leaving the external surface [9]. However, the silicon deposition will make the pore size of HZSM-5 smaller [9], which makes the coke precursor retains in the channel and increases the possibility of carbon deposit. Herein, the construction of microporous 
and mesoporous core-shell composite is an effective way to overcome above drawbacks. The mesoporous shell of core-shell composites can cover the external acid sites of the parent materials, avoiding the further reaction for coke in consequence as well. Moreover, in the mesoporous shell, the feed and products can diffuse freely. The diffusions of large molecules in the catalyst were affected not only by the channel's size but also by the shape, dimension and pore size distribution, etc. For better diffusion, the shell materials with 3-dimension channels and large pore size were typically superior to those with 1-dimension and 2-dimension channels as well as the middle and small pore size. Asima and his coworker found that on FER with one-dimension and a pore size of $0.45 \times 0.55 \mathrm{~nm}$, the toluene and xylenes with a molecular size of $0.57 \mathrm{~nm}$ and $0.58-0.68 \mathrm{~nm}$ have a small yields, compared with its on ZSM-5 with threedimension and a pore size of $0.54 \times 0.56 \mathrm{~nm}$, which attributed to the diffusion limitation [10]. Compared with the $3 \mathrm{D}$ microporous material, 3D mesoporous materials is preferred for its large pore size, what's more, 3D mesoporous materials can be zeolites or any other materials synthesized with template [11, 12].

Shortly, Qian tried the synthesis of 3-dimension mesoporous core-shell materials with Pluronic F108 [13]. In the meanwhile, Qian proposed that the large molecules transport is faster in the cubic mesopores than in the cylinder mesopores, which can diminish pore blocking [13, 14]. Based on above studies, it can be proposed here that the core-shell composite with 3D mesoporous shell have a good application prospect in MTA for its channel connectivity and suitable pore size. F127 is also a typical template in the formation of 3D mesopores and the mesopores synthesized with this template is often larger, which is favorable for the diffusion of large molecules and helpful for impeding the coke formed, therefore it is desirable for such a mesoporous support to be processed for MTA catalysts [15]. In this paper, we choose F127 as a template to try the synthesis of a cubic ordered mesoporous core-shell material with acidic sol-gel coating method. In addition, Ga was loaded on this material for the good aromatization results and such catalyst showed excellent catalytic activity and stability in MTA.

\section{Experimental}

\subsection{Catalyst preparation and characterization}

$3.82 \mathrm{~g}$ of Pluronic F127 was dissolved in $300 \mathrm{~mL}$ of $2 \mathrm{M}$ $\mathrm{HCl}$ at $40^{\circ} \mathrm{C}$ for $30 \mathrm{~min}$. In order to obtain fine dispersion, $4.22 \mathrm{~g}$ of $\mathrm{HZSM}-5$ powder $(\mathrm{Si} / \mathrm{Al}=27)$ was placed into the reaction system under ultrasonic treatment for $30 \mathrm{~min}$. Then, $18 \mathrm{~g}$ of TEOS (tetraethyl orthosilicate) was added dropwisely under moderate stirring. After stirring for $24 \mathrm{~h}$, the mixture was transferred to an autoclave for hydrothermal treatment at $100^{\circ} \mathrm{C}$ for $24 \mathrm{~h}$. The as-synthesized sample was washed with deionized water untill the used water is neutral. After calcination at $550^{\circ} \mathrm{C}$ for $5 \mathrm{~h}$ in static air, the core-shell composite designated as HZ@COMS was obtained, in which $\mathrm{HZ}, \mathrm{C}, \mathrm{O}, \mathrm{M}$ and $\mathrm{S}$ represented the HZSM-5, cubic, ordered, mesoporous and $\mathrm{SiO}_{2}$, respectively. $\mathrm{Ga}_{2} \mathrm{O}_{3} / \mathrm{HZ} @ \mathrm{COMS}$ (hereafter referred as $\mathrm{Ga} / \mathrm{HZ} @$ COMS) was prepared by wet impregnation method with $3 \mathrm{wt} \%$ loading amount using aqueous solution of Gallium nitrate. The resulted mixture was dehydrated overnight at $100^{\circ} \mathrm{C}$ and calcined at $550^{\circ} \mathrm{C}$ for $5 \mathrm{~h}$ in static air. In comparison, we prepared dealuminated ZSM-5 without adding F127 and TEOS by similar procedures in the case of preparing the core-shell composite. Such catalyst was denoted as HZ-Acid. The used Ga/HZ@COMS was regenerated at $750^{\circ} \mathrm{C}$ for $5 \mathrm{~h}$ in static air and was denoted as $\mathrm{Ga} / \mathrm{HZ} @$ COMS-R.

The low-angle and large-angle X-ray scattering measurements were carried out on an X-ray diffractometer (D/ max-RB, Rigaku, Japan) equipped with Ni-filtered $\mathrm{Cu}-\mathrm{K} \alpha$ radiation which was generated at an operation voltage of $40 \mathrm{kV}$ and a filament current of $35 \mathrm{~mA} . \mathrm{N}_{2}$ adsorption-desorption isotherms were measured at $-196^{\circ} \mathrm{C}$ on a Micromeritics ASAP 2405 analyzer. Prior to the measurement, each sample $(100 \mathrm{mg})$ was degassed in a vacuum at $300^{\circ} \mathrm{C}$ for $10 \mathrm{~h}$ at least. The specific surface area and pore size distribution of pores were calculated by the Brunauer-Emmett-Teller (BET) and Density Functional Theory (DFT) methods, respectively. The micropore volume and surface area were calculated by the t-plot method. The mesopore and macropores volume and surface area were calculated by Barrett-Joyner-Halenda (BJH) adsorption cumulative volume of pores between 1.7 and $300 \mathrm{~nm}$ diameter. Scanning electron microscopy (SEM) imagines was obtained on a SEM microscope (HITACHI SU-8010, Japan) at an operation voltage of $5-15 \mathrm{kV}$. Transmission electron microscopy (TEM) images and energy dispersive spectroscopy-X (EDX) were recorded on a TEM microscope (JEOL JEM-2100 F, Japan) with an accelerating voltage of $200 \mathrm{kV}$. $\mathrm{NH}_{3}$-TPD with a Micromeritics AutoChem II 2920 in the range of $150-600^{\circ} \mathrm{C}$ at a ramp rate of $20^{\circ} \mathrm{C} / \mathrm{min}$, and the desorbed ammonia was monitored by a gas chromatograph with a TCD detector. The Py-IR spectra were recorded with a FT-IR spectrometer (Bruker Vertex 70 , Germany). The catalyst samples were ground into a fine powder and pressed into self-supported discs. The disc was placed in the centre of IR cell. Firstly, the sample discs were heated to $100^{\circ} \mathrm{C}$ at $10^{\circ} \mathrm{C} / \mathrm{min}$ under vacuum and kept for $1 \mathrm{~h}$. Secondly, the sample discs were exposed to pyridine until adsorption saturation at $150^{\circ} \mathrm{C}$ under vacuum for $1 \mathrm{~h}$. Then, the excess Py in the IR cell was removed. 
After each step, spectra were recorded at room temperature. Thermal gravimetric analysis (TGA) was carried out on a thermal gravimetric analyzer (Perkin Elmer TGA, US). The sample was heated from 10 to $750^{\circ} \mathrm{C}$ in air at a heating rate of $10^{\circ} \mathrm{C} / \mathrm{min}$.

\subsection{Catalytic test and products analysis}

MTA reaction was carried out in a continuous-flow fixedbed reactor with an inner diameter of $16 \mathrm{~mm}$. The catalyst particles with 40-60 mesh were obtained with compression method. $2.5 \mathrm{~g}$ catalyst was loaded in the central zone of the reactor. A thermocouple reaching into the middle of the reactor was used to measure the temperature of the catalyst bed during the reaction. The catalyst was activated at $410^{\circ} \mathrm{C}$ for $1 \mathrm{~h}$ under nitrogen flow before reaction. With a WHSV (weight hourly space velocity) of $2.7 \mathrm{~h}^{-1}$ at $0.1 \mathrm{MPa}$, the methanol was pumped into the reactor by an injection pump. The methanol was mixed with nitrogen $(30 \mathrm{~mL} / \mathrm{min})$ in the catalytic tests. The products were analyzed on a gas chromatograph Agilent 7890A which equipped with FID detector and capillary column (HP-5). The conversion of methanol and the yields of products were calculated with the follow equals: where, $m$ represents the mass, $A$ represents the peak area of product, $f$ represents the correction factor. Dimethyl ether was produced during MTA. In this occasion, however, methanol and dimethyl ether were both calculated as the inlet material, considering the latter is easy to be produced over a catalyst with very weak acids [16]. Longevity was defined as the total reaction time until the oil phase disappeared in products.

\section{Results and discussion}

\subsection{Chemical and physical properties of catalysts}

As it shown in Fig. 1a, the low-angle XRD patterns of HZ@COMS and Ga/HZ@COMS demonstrated small peak diffraction around at $2 \theta=0.6^{\circ}$ corresponding to (110) reflection of SBA-16, which indicated that ordered mesopore may appeared [17]. As it shown in Fig. 1b, for $\mathrm{HZ}$, the characteristic diffraction peaks $\left(2 \theta=8.0^{\circ}, 9.0^{\circ}\right.$, $14.8^{\circ}, 24.0^{\circ}, 29.8^{\circ}, 45^{\circ}$ and $\left.46^{\circ}, \mathrm{JCPDS}=44-0003\right)$ correspond to its crystalline structure. For HZ@COMS and Ga/HZ@COMS, such XRD patterns were still completed

Conversion of methanol $=\frac{m(\text { inlet } \text { methanol })-m(\text { outlet methanol })}{m(\text { inlet } \text { methanol })} \times 100 \%$

Selectivity of products $=\frac{\text { Ai fi }}{\sum \text { Ai fi }} \times 100 \%$

but merely weaker than those of the parent $\mathrm{HZ}$ sample, as a result of the content of zeolite phase in the composite material was about $40-45 \mathrm{wt} \%$ (it goes from the

Yield of oil $=$ conversion of methanol $\times$ selectivity of total organic products $\times 100 \%$

Fig. 1 Low-angle XRD of HZ@COMS and Ga/HZ@ COMS (a) and wide-angle XRD of HZ, HZ@COMS and Ga/ HZ@COMS (b)
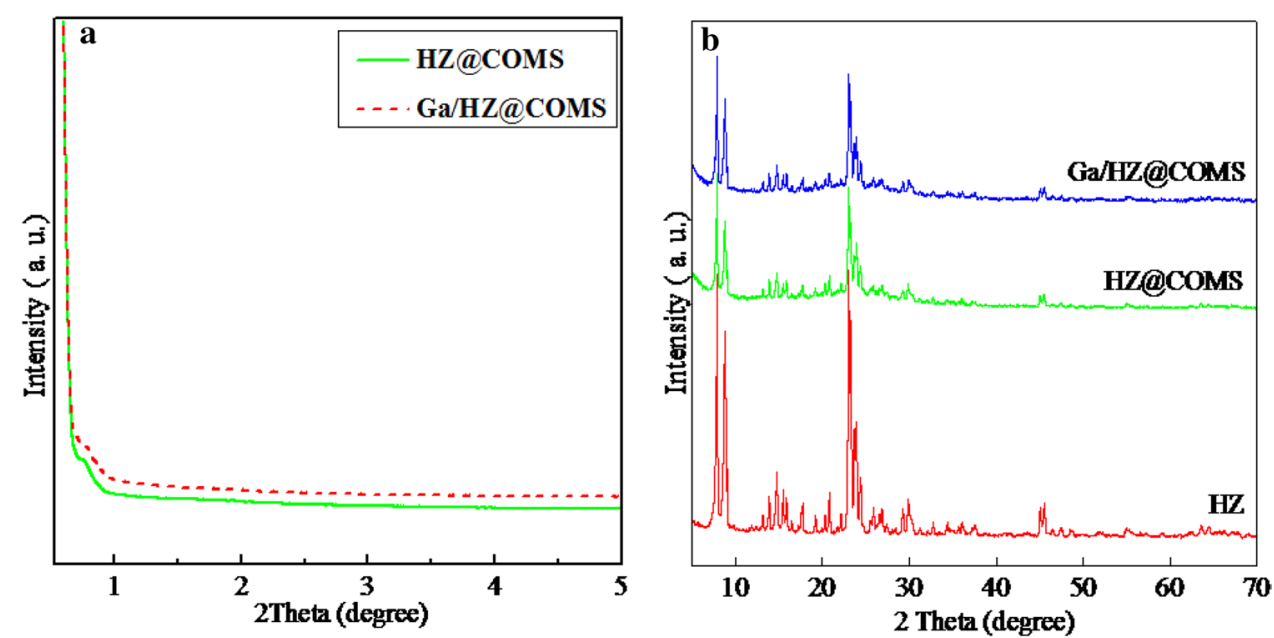
preparation procedure). Compared with HZ@COMS, the XRD patterns of $\mathrm{Ga} / \mathrm{HZ} @ \mathrm{COMS}$ had no changes with the introduction of $\mathrm{Ga}_{2} \mathrm{O}_{3}$, which may indicate the fine dispersion of $\mathrm{Ga}_{2} \mathrm{O}_{3}$ particles.

As it shown in Fig. 2a, for $\mathrm{HZ}$ the initial part of $\mathrm{N}_{2}$ adsorption and desorption isotherm is of type corresponding to a microporous framework. For HZ@COMS and Ga/HZ@COMS their isotherms both present H2 hystersis loops within the relative pressure $\mathrm{P} / \mathrm{P}_{0}$ range of $0.40-0.75$, and such isotherms are of type IV. Such $\mathrm{N}_{2}$ adsorption and desorption results may suggest the existence of the connective $3 \mathrm{D}$ mesopores $[13,17,18]$. At the same time, the micro-meso hierarchical pore structure was made in the construction of the core-shell structure. This situation was proved by the results in Fig. 2 b, the pore size distribution of $\mathrm{HZ}$ present one peak within $2 \mathrm{~nm}$ and several peaks ranging from 2 to $9 \mathrm{~nm}$. These pores may derived from the core-shell connectivity, piled pore or mesoporous shell $\mathrm{SiO}_{2}$. In addition, the addition of $\mathrm{Ga}$ had obvious effect on the distribution of mesopores. Combined with Table 1, the introduction of mesoporous shell $\mathrm{SiO}_{2}$ on core HZSM-5 not only makes the specific surface areas increase efficiently (from 408 to $620 \mathrm{~m}^{2} \mathrm{~g}^{-1}$ ), but also retained micropore volume of pristine material. After the addition of Ga on HZ@COMS, the surface area of micropore and mesopore increased from 197 to $220 \mathrm{~m}^{2} \mathrm{~g}^{-1}$ and from 423 to $494 \mathrm{~m}^{2} \mathrm{~g}^{-1}$, respectively. The volume of micropore and mesopore decreased from 0.18 to $0.17 \mathrm{~cm}^{3} \mathrm{~g}^{-1}$ and from 0.27 to $0.21 \mathrm{~cm}^{3} \mathrm{~g}^{-1}$ meanwhile, respectively. These results indicated that the effect of $\mathrm{Ga}_{2} \mathrm{O}_{3}$ particles on mesopore were more obvious than that on micropore, which suggested that $\mathrm{Ga}_{2} \mathrm{O}_{3}$ particles were probably located inside the mesopore. At the same time, the mesopore can't be affected by the $\mathrm{Ga}_{2} \mathrm{O}_{3}$ compared with HZ@COMS. This indicated that $\mathrm{Ga}_{2} \mathrm{O}_{3}$ particles were deposited uniformly and didn't block the mesopore.

As it shown in Fig. 3a-d, a micro/mesoporous core-shell composite was synthesized, in which HZSM-5 was core and cubic ordered mesoporous silica with a pore size of about $10 \mathrm{~nm}$ was shell. The sharp borderline existed between shell with a thickness of $0.5 \mu \mathrm{m}$ and core shown in Fig. 3a-c. As shown in Fig. 3d, the size of connection between core and shell was smaller than the cubic mesopore, which can generate hierarchical pores. Figure 4 shows the TEM of Ga/HZ@COMS. After the loading of $\mathrm{Ga}$, the core-shell structure was still kept well and no large Ga particles were observed. In order to observe the distribution of Ga, TEM/EDX of Ga/HZ@COMS was
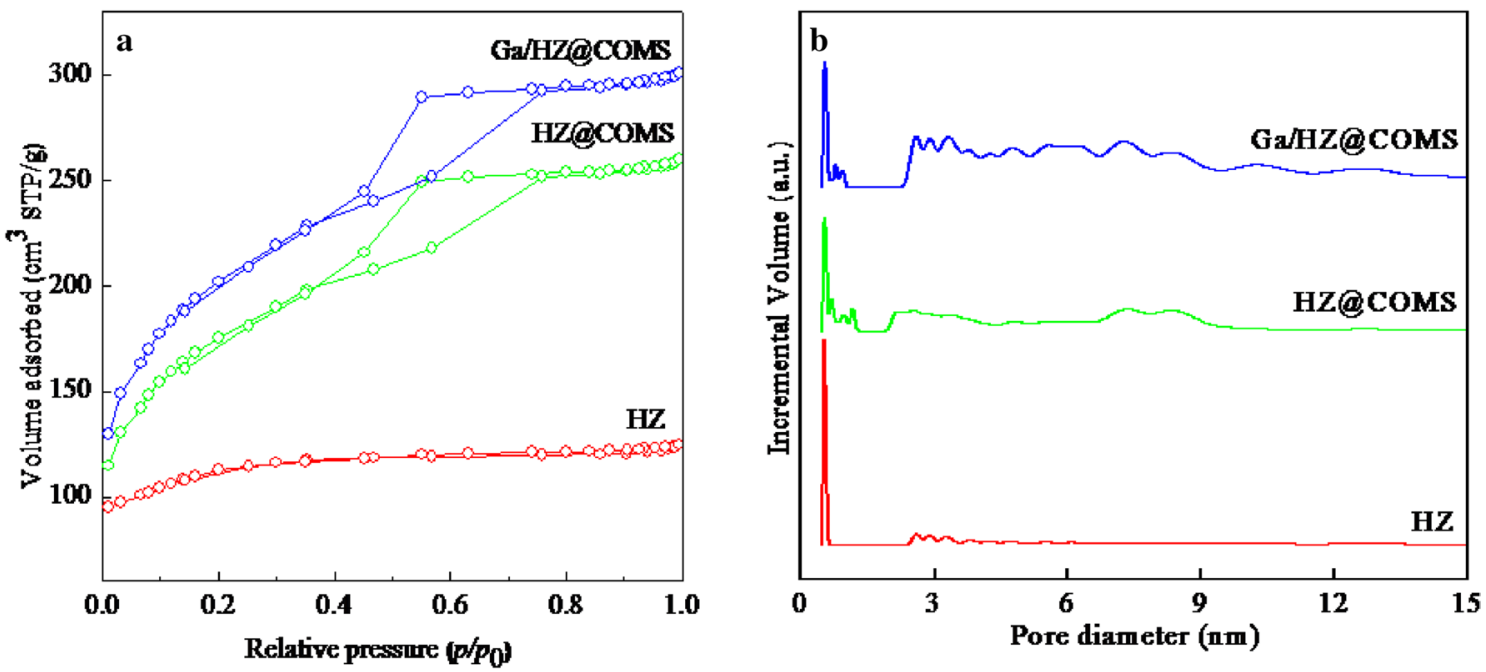

Fig. $2 \mathrm{~N}_{2}$ physisorption isotherms (a) with pore size distribution (b) of HZ, HZ@COMS and Ga/HZ@COMS

Table 1 Physical properties of HZ,HZ@COMS and Ga/HZ@ COMS

\begin{tabular}{llllllll}
\hline Sample & $\begin{array}{l}\mathrm{S}_{\mathrm{BET}} \\
\left(\mathrm{m}^{2} \mathrm{~g}^{-1}\right)\end{array}$ & $\begin{array}{l}\mathrm{S}_{\text {micro }} \\
\left(\mathrm{m}^{2} \mathrm{~g}^{-1}\right)\end{array}$ & $\begin{array}{l}\mathrm{S}_{\mathrm{ex}} \\
\left(\mathrm{m}^{2} \mathrm{~g}^{-1}\right)\end{array}$ & $\begin{array}{l}\mathrm{V}_{\text {micro }} \\
\left(\mathrm{cm}^{3} \mathrm{~g}^{-1}\right)\end{array}$ & $\begin{array}{l}\mathrm{V}_{\text {meso }} \\
\left(\mathrm{cm}^{3} \mathrm{~g}^{-1}\right)\end{array}$ & $\begin{array}{l}\mathrm{D}_{\text {micro }} \\
(\mathrm{nm})\end{array}$ & $\begin{array}{l}\mathrm{D}_{\text {meso }} \\
(\mathrm{nm})\end{array}$ \\
\hline $\mathrm{HZ}$ & 408 & 214 & 193 & 0.14 & 0.09 & 0.57 & - \\
$\mathrm{HZ}$ @COMS & 620 & 197 & 423 & 0.18 & 0.27 & 0.57 & $3.2,10.0$ \\
Ga/HZ@COMS & 714 & 220 & 494 & 0.17 & 0.21 & 0.57 & $3.2,10.0$ \\
\hline
\end{tabular}

$S_{B E T}$ BET surface areas, $S_{\text {micro }}$ micropore areas, $S_{e x}$ external areas, $V_{\text {micro }}$ micropore volume, $V_{\text {meso }}$ mesopore volume, $D_{\text {meso }}$ mesopore diameter, $D_{\text {micro }}$ micropore diameter 
Fig.3 TEM of HZ@COMS (a-d)
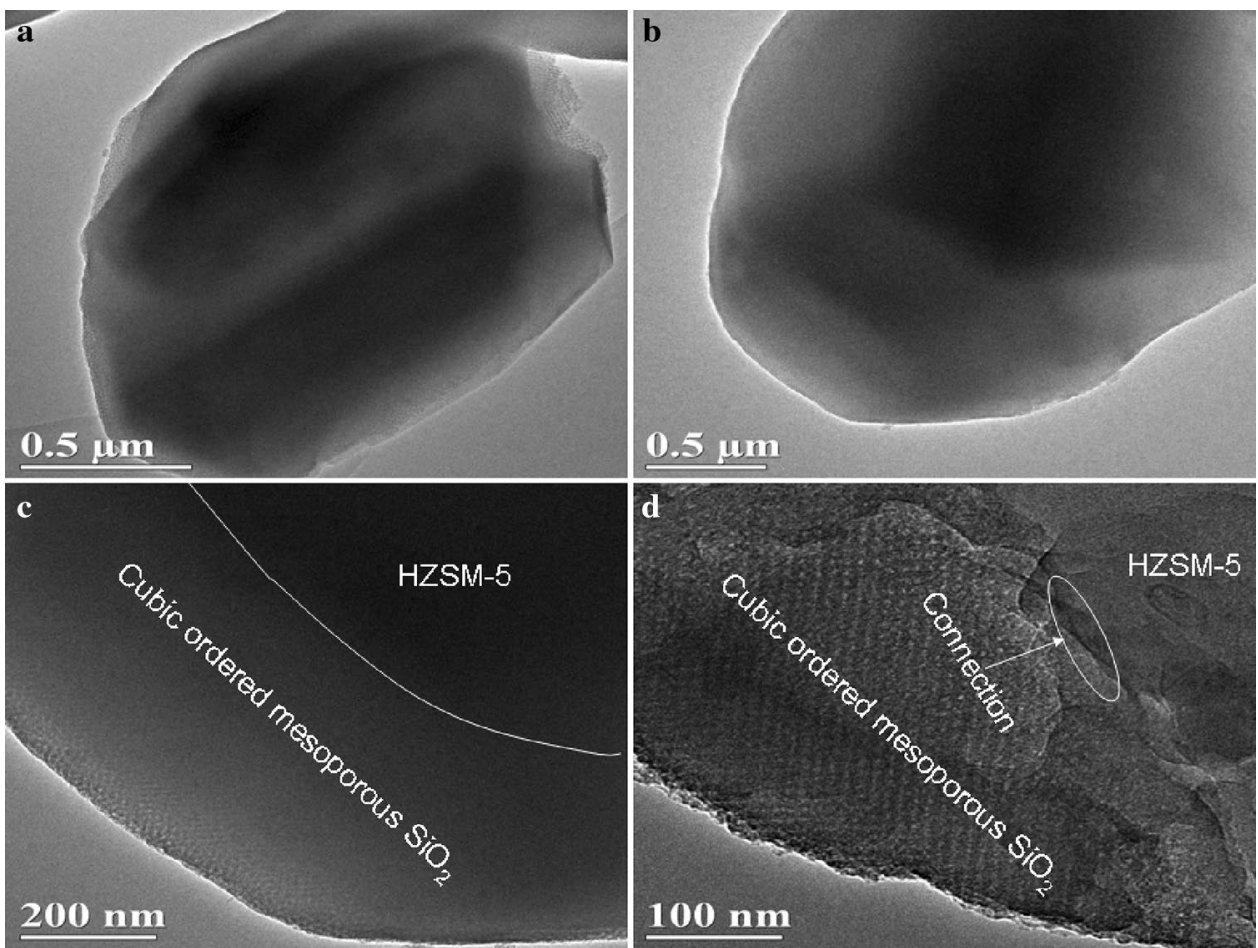

conducted. The EDS image of Ga/HZ@COMS identified the presentation of $\mathrm{Ga}$. According to the element mapping of $\mathrm{Ga} / \mathrm{HZ} @ \mathrm{COMS}, \mathrm{Al}$ was distributed in the core HZSM5. For $\mathrm{Ga}, \mathrm{Si}, \mathrm{Al}$ and $\mathrm{O}$, they were distributed in the shell $\mathrm{SiO}_{2}$ and core HZSM-5. However, the Ga was mainly distributed in the shell $\mathrm{SiO}_{2}$; this indicated that the $\mathrm{Ga}$ was mainly located in the mesopore of shell $\mathrm{SiO}_{2}$.

The core-shell materials didn't show so good dispersion in SEM images (Fig. 5), which was due to the pristine zeolites agglomeration shown in Fig. 5a, c. As it shown in Fig. 5b, the shell was synthesized by layer growth in accordance with previous studies [19]. Additionally, core-shell composite was spheroid shown in Fig. 5c, while the HZSM-5 with a thin layer of shell (in the green circle) kept pristine zeolites structure with hexagonally prismatic shapes shown in Fig. 5d. Based on above results, we proposed such a mechanism shown in Fig. 6. Firstly, the HZSM-5 was treated with hydrochloric acid. Thus, the surface of HZSM-5 zeolite was modified. Then, TEOS hydrolysis with the aid of hydrochloric acid and covered the core HZSM-5. Finally, a cubic ordered mesoporous shell synthesized with F127 as template and TEOS as Si source surrounded the HZSM-5, then a core-shell composite was obtained.

$\mathrm{NH}_{3}$-TPD patterns of all catalysts showed two desorption peaks in Fig. 7a, in which the peak at low temperature peak $\left(180^{\circ} \mathrm{C}\right)$ and the high temperature peak at $\left(400^{\circ} \mathrm{C}\right)$ were attributed to weak and strong acid sites, respectively [20]. It can be seen obviously that the areas of the two peaks decreased remarkably and simultaneously the centers of the two peaks shifted toward lower temperature compared to that of the pristine HZSM-5. It can be induced that both composite materials, HZ@ COMS and Ga/HZ@COMS, contained less a half of the zeolite phase. In addition, for core-shell materials, the external strong acid sites of HZSM- 5 were covered by $\mathrm{SiO}_{2}$ to some extent. As a result, the areas of the hightemperature peaks and low-temperature peaks of HZ@ COMS and Ga/HZ@COMS were all smaller than the parent zeolite. In addition, the area of low temperature peak for Ga modified catalyst was bigger than that of HZ@ COMS slightly, which are contributed to the introduction of weak acid sites of the $\mathrm{Ga}_{2} \mathrm{O}_{3}$.

Py-IR was used to study the nature of acidic sites. As it shown in Fig. 7b, three bands at 1546, 1490 and $1445 \mathrm{~cm}^{-1}$ were existed in HZ and HZ@ COMS. These bands at 1546, 1490 and $1445 \mathrm{~cm}^{-1}$ were attributed to Brønsted, Brønsted + Lewis and Lewis acid sites, respectively [21]. This indicated that the acid sites weren't removed during the preparation of core-shell material. At the same time, the intensity of Lewis acid peak decreased slightly in HZ@ COMS compared with HZ. This was due to the fact that the introduction of $\mathrm{Si}-\mathrm{OH}$ can decrease the amount of Lewis acid sites [22]. It was noted that a new band at $1455 \mathrm{~cm}^{-1}$ appeared for Ga/HZ@COMS compared with other catalysts. The band at $1455 \mathrm{~cm}^{-1}$ was generally the reflection of pyridine on Lewis (PyL) [23, 24]. Such Lewis acid was derived from the interaction of $\mathrm{Ga}$ and $\mathrm{Al}[22,25]$. This 
Fig. 4 TEM and EDX spectra of elemental mapping results of Ga/HZ@COMS
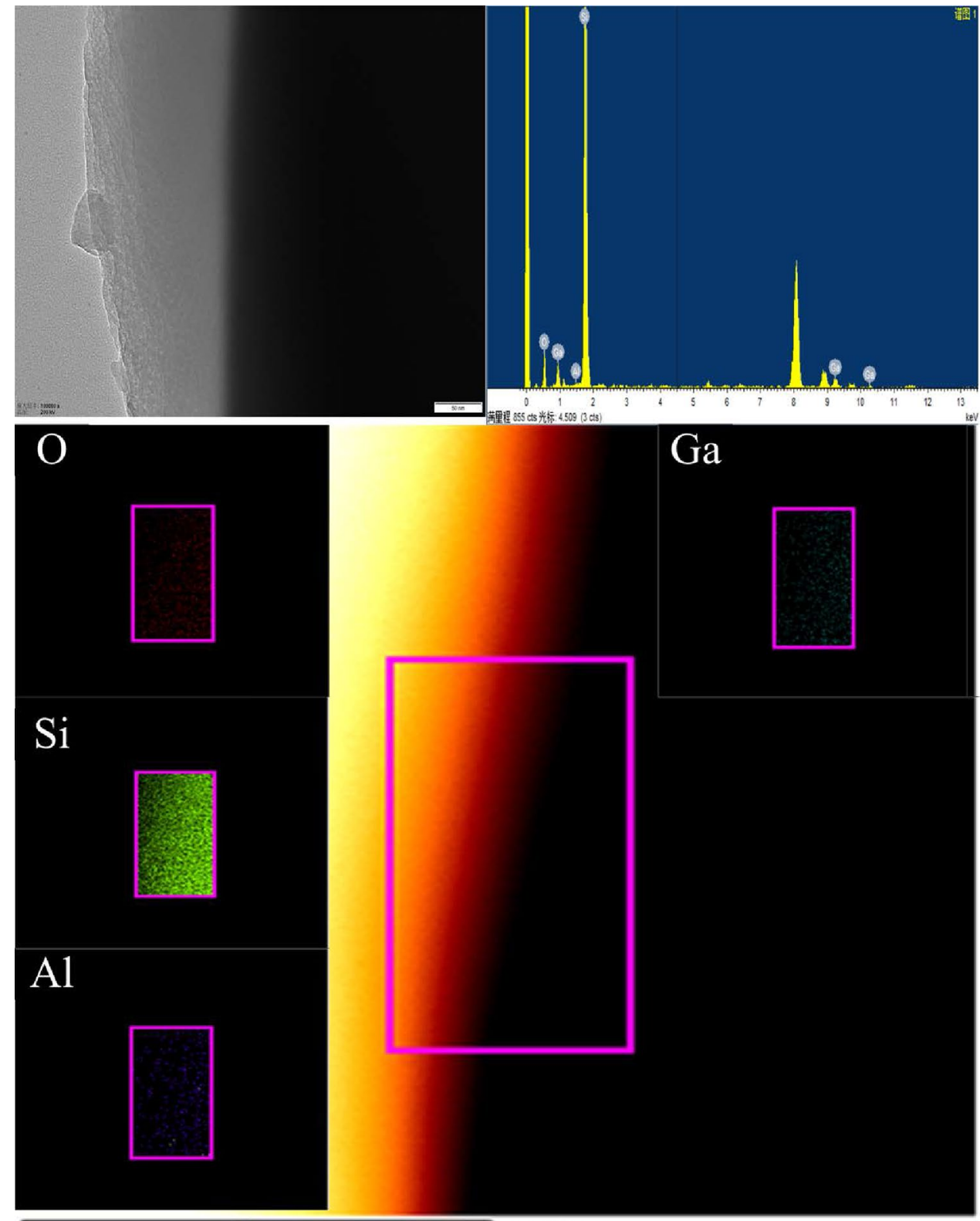

$30 \mathrm{~nm}$

theme 1 indicated that some $\mathrm{Ga}_{2} \mathrm{O}_{3}$ particles were located in the core HZSM-5.

\subsection{MTA reaction on core-shell catalysts}

As it shown in Fig. 8a, b, the longevity of $\mathrm{HZ}$ increased from 16 to $42 \mathrm{~h}$ after the loading of shell $\mathrm{SiO}_{2}$. At the same time, after the introduction of silica shell outside the $\mathrm{HZ}$ zeolite, the $\mathrm{C}_{9}+$ hydrocarbons amount decreased from 64 to $41 \%$ remarkably as shown in Table 2 . In general, the molecule size of $\mathrm{C}_{9}+$ hydrocarbons beyond the pore size of HZ. So the $\mathrm{C}_{9}+$ hydrocarbons formed over the external acid sites. This indicated that the external acid sites were covered by shell $\mathrm{SiO}_{2}$ during the preparation of core shell material HZ@COMS. At the same time, in 3D hierarchical porous shell structure the large molecules have better diffusion than in core HZ. Thus, the side reaction was avoided and the longevity improved. After the loading of $\mathrm{Ga}_{2} \mathrm{O}_{3}$, the longevity of HZ@COMS further increased from 42 to $56 \mathrm{~h}$. Comparing the products distribution over HZ@COMS and Ga/HZ@COMS as shown in Table 2, it can be found that the BTX increased while the $\mathrm{C}_{2}-\mathrm{C}_{5}$ and $\mathrm{C}_{9}+$ decreased over the Ga/HZ@COMS, suggesting that the catalytic reforming of products occurred in nanoscale reactor for $\mathrm{Ga} /$ HZ@COMS. This was contributed to dealkylation reaction of $\mathrm{C}_{9}+$ hydrocarbons on the new Lewis acid sites. After regeneration of $\mathrm{Ga} / \mathrm{HZ} @ \mathrm{COMS}$, the longevity of catalyst decreased slightly but the distribution of products were 
Fig. 5 SEM of HZ@COMS (a) and $\mathrm{Ga} / \mathrm{HZ} @ \mathrm{COMS}(\mathbf{b}-\mathbf{d})$
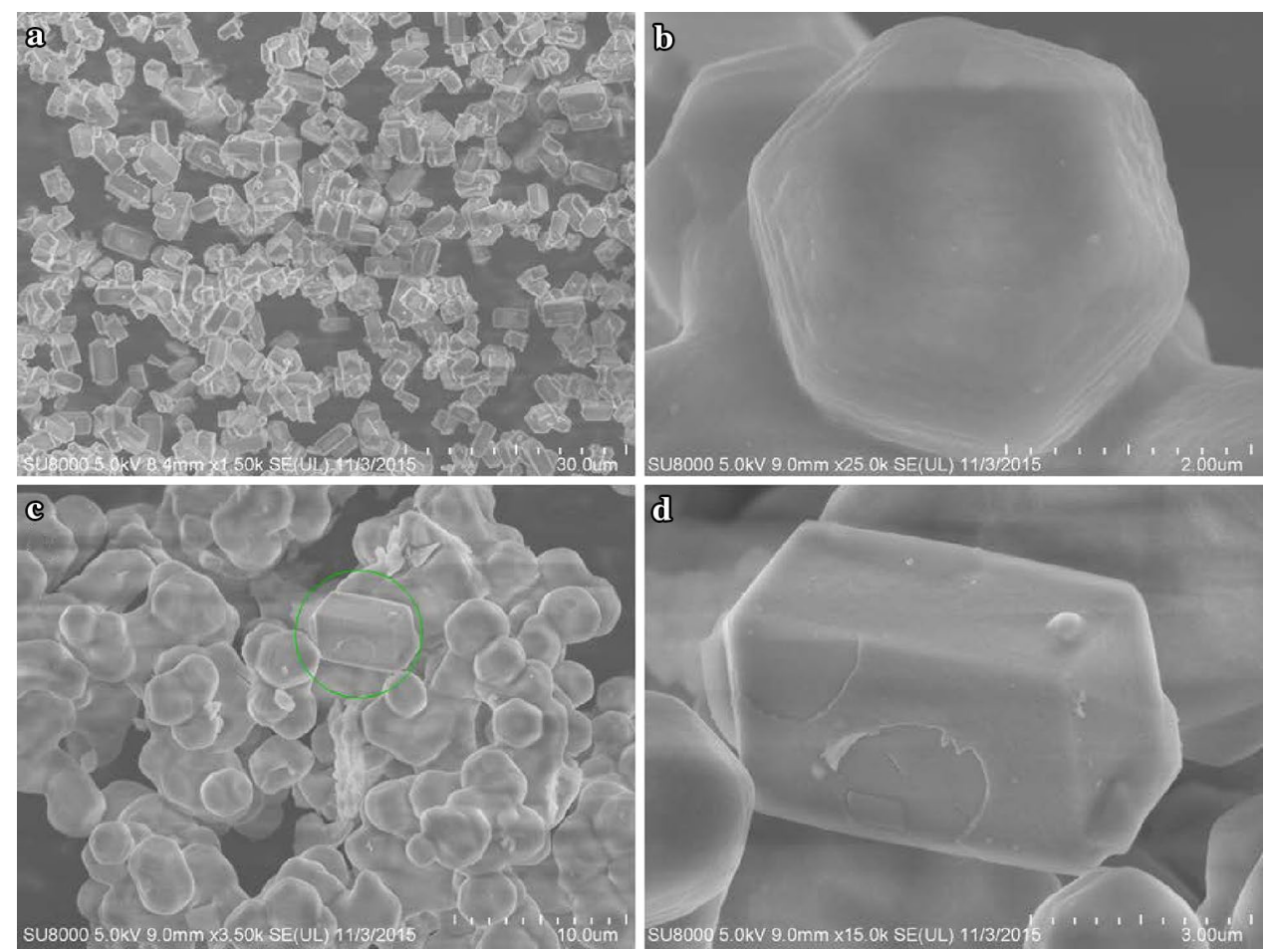

Fig. 6 Mechanism of HZ@ COMS preparation

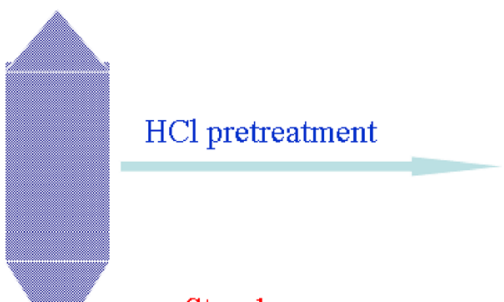

Step 1

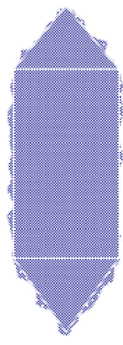

TEOS hydrolysis

$\mathrm{F} 127 \mathrm{HCl}$

Step 2

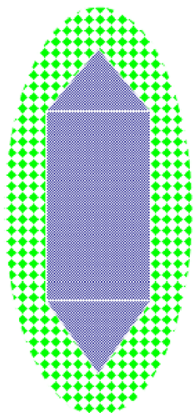

HZSM-5
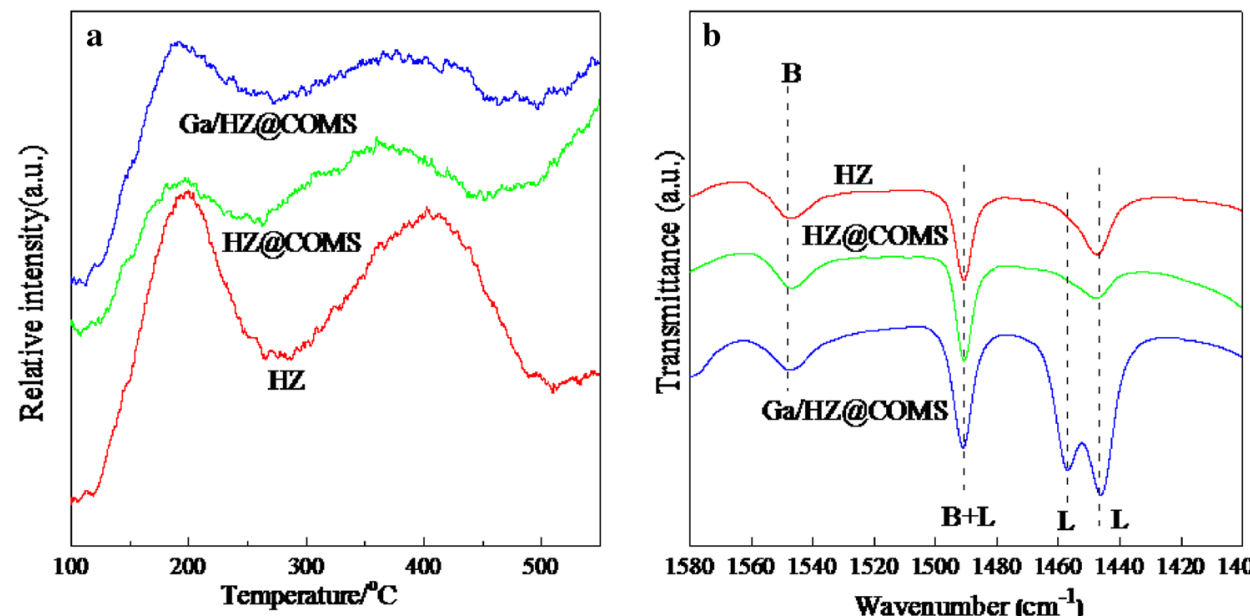

1580156015401520150014801460144014201400 Wavenumber $\left(\mathrm{cm}^{-1}\right)$ (b) of HZ, HZ@COMS and Ga/ HZ@COMS
Fig. $7 \mathrm{NH}_{3}$-TPD (a) and Py-IR 

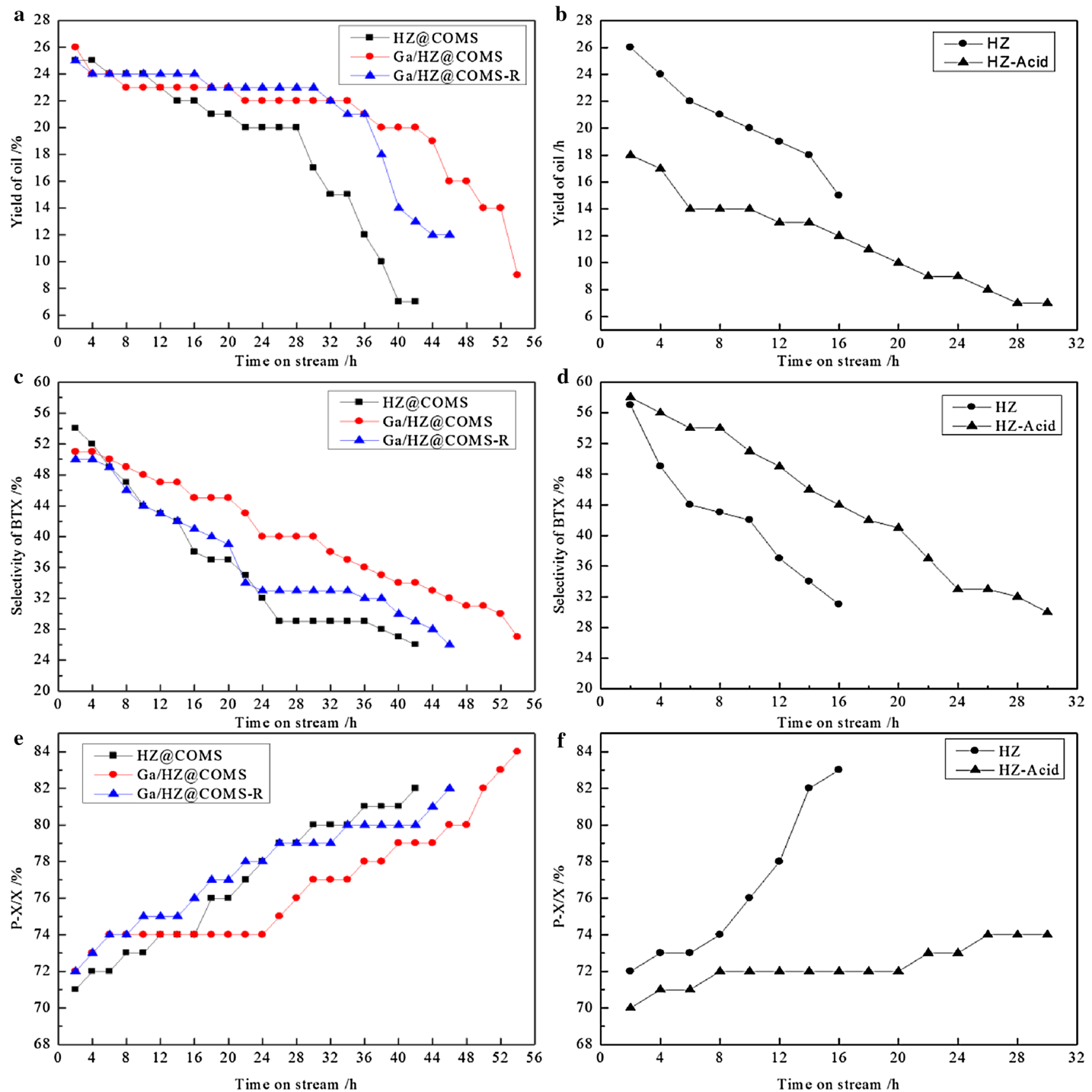

Fig. 8 Yield of oil (a, b), Selectivity of BTX (c, d) and P-X/X (e, f) over HZ@COMS, Ga/HZ@COMS, Ga/HZ@COMS-R, HZ and HZ-Acid

basically unchanged. In order to study the effect of external acid sites on the longevity and products, the reaction over HZ-Acid was conducted. After acid sites were removed the longevity increased remarkably from 16 to $30 \mathrm{~h}$ shown in Fig. 8b. At the same time, the $\mathrm{C}_{9}+$ decreased from 64 to $39 \%$ and the BTX increased from 31 to $44 \%$ as shown in Table 2, suggesting that the external acid sites favored the side reaction. For HZ-Acid, the yield of oil decreased compared with HZ. This was because large amount of light hydrocarbons $\mathrm{C}_{2}-\mathrm{C}_{5}$ can't convert efficiently on the reduced acid sites. But for $\mathrm{Ga} / \mathrm{HZ} @ \mathrm{COMS}$ with higher yield of oil, cubic mesopore loaded with $\mathrm{Ga}_{2} \mathrm{O}_{3}$ can be regarded as a nanoscale reactor. Two reasons were contributed to this phenomenon. One reason was that the shell $\mathrm{SiO}_{2}$ covered the external acid sites and inhibited the coke reaction of $\mathrm{C}_{9}+$. Another reason was that $\mathrm{C}_{9}+$ reacted with $\mathrm{C}_{2}-\mathrm{C}_{5}$ over $\mathrm{Ga}_{2} \mathrm{O}_{3}$ in cubic mesopore. Thus, some $\mathrm{C}_{2}-\mathrm{C}_{5}$ and $\mathrm{C}_{9}+$ were diffused from $\mathrm{HZ}$ to the nanoscale reactor and converted into BTX. 
Table 2 Product distributions over HZ@COMS, Ga/HZ@ COMS, Ga/HZ@COMS-R HZ and HZ-Acid in MTA reaction ${ }^{\mathrm{a}}$

\begin{tabular}{llllllllll}
\hline Catalyst & Cov. (\%) & \multicolumn{9}{l}{ Product distribution (\%) } & \multicolumn{2}{c}{ BTX $^{\mathrm{i}}$} \\
\cline { 2 - 9 } & & $\mathrm{C}_{2}-\mathrm{C}_{5}{ }^{\mathrm{b}}$ & $\mathrm{B}^{\mathrm{c}}$ & $\mathrm{T}^{\mathrm{d}}$ & $\mathrm{o}-\mathrm{X}^{\mathrm{e}}$ & $\mathrm{p}-\mathrm{X}^{\mathrm{f}}$ & $\mathrm{m}-\mathrm{X}^{\mathrm{g}}$ & $\mathrm{C}_{9}+^{\mathrm{h}}$ & \\
\hline HZ@COMS & 100 & 21 & 2 & 9 & 2 & 20 & 5 & 41 & 38 \\
Ga/HZ@COMS & 100 & 16 & 2 & 9 & 3 & 25 & 6 & 39 & 45 \\
Ga/HZ@COMS-R & 100 & 17 & 1 & 7 & 2 & 25 & 6 & 42 & 41 \\
HZ & 100 & 5 & 1 & 7 & 1 & 19 & 3 & 64 & 31 \\
HZ-Acid & 100 & 17 & 1 & 18 & 1 & 18 & 6 & 39 & 44 \\
\hline
\end{tabular}

Product distribution was calculated by area normalization method with relative error not exceeding $0.5 \%$

${ }^{a}$ Reaction conditions: $0.1 \mathrm{MPa}, 410^{\circ} \mathrm{C}$, WHSV $=2.7 \mathrm{~h}^{-1}$, Time-on-stream $=16 \mathrm{~h}$

${ }^{\mathrm{b}} \mathrm{C}_{2-5}$ aliphatic hydrocarbons, ${ }^{\mathrm{c}}$ Benzene, ${ }^{\mathrm{d}}$ Toluene, ${ }^{\mathrm{e}}$ ortho-Xylene, ${ }^{\mathrm{f}}$ para-Xylene, ${ }^{\mathrm{g}}$ meta-Xylene, ${ }^{\mathrm{h}} \mathrm{C}_{9}$ and $\mathrm{C}_{9}+$ aromatics, ${ }^{\mathrm{i}} \mathrm{BTX}$ benzene, toluene and xylene

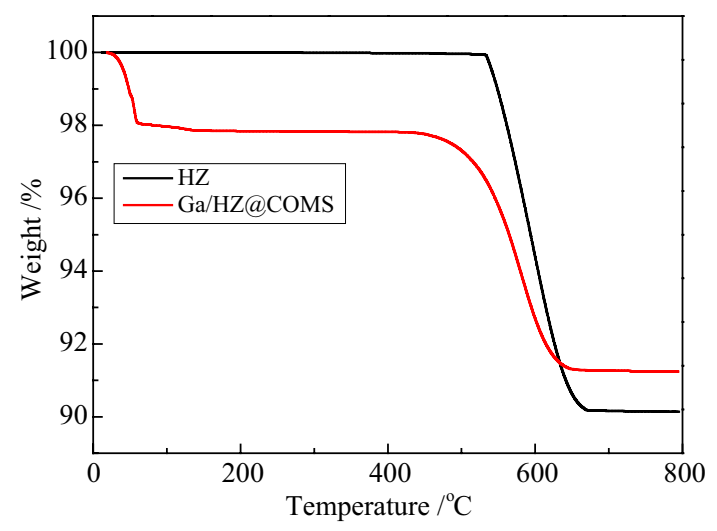

Fig. 9 TGA profiles of $\mathrm{HZ}$ and $\mathrm{Ga} / \mathrm{HZ} @ \mathrm{COMS}$

It was interesting that for all catalysts the selectivity of para-xylene in xylenes increased with the time online. This was due to the fact that the channel blockage of zeolite by carbonaceous deposits was occurred during the reaction, perhaps [26]. In order to study rate of coke, TGA was conducted to be shown in Fig. 9. Corresponding to the coke amount, the weight loss between 300 and $750^{\circ} \mathrm{C}$ [27]. As it shown in Fig. 9, the coked HZ shows a weight loss of 9.9\% after $12 \mathrm{~h}$ on stream. In comparison, the coked Ga/HZ@ COMS shows a weight loss of $6.6 \%$ after $54 \mathrm{~h}$ on stream. These results indicated that the average rate of coke formation on the Ga/HZ@COMS was only about $0.2 \%$ per hour, much lower than the $0.8 \%$ formation rate observed on the HZ. As a consequence of all of these, the Ga/HZ@COMS has better coke resistance and higher longevity of catalyst compared with HZ.

\section{Conclusions}

A core-shell composite with HZSM-5 as core and cubic ordered 3D hierarchical mesoporous silica as shell was synthesized using Pluronic F127 as mesoporous structural template. The ordered cubic mesopore and shell can improve the products diffusion and adjust the external acid properties to a large extent. Consequently the core-shell composite exhibited higher coke-resistance, which increased longevity of catalyst from 10 to $42 \mathrm{~h}$. After loading $\mathrm{Ga}$, the cubic ordered mesopore offered nanoscale reactor in the catalytic reforming of $\mathrm{C}_{9}+$ hydrocarbons, which further improved longevity of catalyst $(54 \mathrm{~h})$ and selectivity of BTX (50\%) and such catalyst has good regeneration ability.

Acknowledgements The authors would like to acknowledge the financial support from the National Natural Science Foundation of China (21406251), and the scientific and technological department of Liaoning Province (No. 2013020097), the educational department of Liaoning Province (Nos. LJQ2015062 and LJQ2015296) and the scientific and technological department of Fushun (FSKJHT201376).

\section{References}

1. A.A. Gaile, G.D. Zalishchevskii, A.S. Erzhenkov, L.L. Koldobskaya, Benzene separation from the benzene fraction of reformer naphtha by extractive rectification with $N$-methylpyrrolidonesulfolane mixtures. Russ. J. Appl. Chem. 81, 1375-1381 (2008)

2. F. Wang, W.Y. Xiao, G.M. Xiao, Atomic layer deposition of zinc oxide on HZSM-5 template and its methanol aromatization performance. Catal. Lett. 145, 860-867 (2015)

3. G.Q. Zhang, T. Bai, T.F. Chen, W.T. Fan, X. Zhang, Conversion of methanol to light aromatics on Zn-modified nano-HZSM-5 zeolite catalysts. Ind. Eng. Chem. Res. 53, 14932-14940 (2014)

4. K. Melánová, J. Klevcov, L. Beneš, J. Svoboda, V. Zima, New layered functionalized titanium(IV) phenylphosphonates. J. Phys. Chem. Solids 73, 1452-1455 (2012)

5. A.A. Rownaghi, J. Hedlund, Methanol to gasoline-range hydrocarbons: influence of nanocrystal size and mesoporosity on catalytic performance and product distribution of ZSM-5. Ind. Eng. Chem. Res. 50, 11872-11878 (2011)

6. K. Zhang, Y. Liu, J. Zhao, C. Liu, Hierarchical porous ZSM-5 zeolite synthesized by in situ zeolitization and its coke deposition resistance in aromatization reaction Chinese. Chin. J. Chem. 30, 597-603 (2012)

7. A.A. Rownaghi, F. Rezaei, J. Hedlund, Uniform mesoporous ZSM-5 single crystals catalyst with high resistance to coke 
formation for methanol deoxygenation. Micropor. Mesopor. Mat. 151, 26-33 (2012)

8. S. Kumar, A.K. Sinha, S.G. Hegde, S. Sivasanker, Influence of mild dealumination on physicochemical, acidic and catalytic properties of H-ZSM-5. J. Mol. Catal. A: Chem. 154, 115-120 (2000)

9. M. Niwa, M. Kato, T. Hattori, Y. Murakami, Fine control of the pore-opening size of zeolite zsm- 5 by chemical vapor-deposition of silicon methoxide. J. Phys. Chem. 90, 6233-6237 (1986)

10. A. Sultana, T. Fujitani, Conversion of levulinic acid to BTX over different zeolite catalysts. Catal. Commun. 88, 26-29 (2017)

11. M. Kubu, N. Zilkova, S.I. Zones, C.Y. Chen, S. Al-Khattaf, J. Cejka, Three-dimensional 10-ring zeolites: the activities in toluene alkylation and disproportionation. Catal. Today 259, 97-106 (2016)

12. S. Reddy, R. Du, L.X. Kang, N.N. Mao, J. Zhang, Three dimensional CNTs aerogel/MoSx as an electrocatalyst for hydrogen evolution reaction. Appl. Catal B-Environ. 194, 16-21 (2016)

13. L. Zhang, Z.X. Jiang, Y. Yu, C.S. Sun, Y.J. Wang, H.Y. Wang, Synthesis of core-shell ZSM-5@meso-SAPO-34 composite and its application in methanol to aromatics. RSC Adv. 5, 5582555831 (2015)

14. X. Qian, D. Xiong, A.M. Asiri, S.B. Khan, M.M. Rahman, H. $\mathrm{Xu}, \mathrm{D}$. Zhao, A facile route to cage-like mesoporous silica coated ZSM-5 combined with Pt immobilization. J. Mater. Chem. A 1, 7525-7532 (2013)

15. P. Forzatti, L. Lietti, Catalyst deactivation. Catal. Today 52, 165181 (1999)

16. J. Zhang, W. Qian, C. Kong, F. Wei, Increasingpara-Xylene selectivity in making aromatics from methanol with a surfacemodified Zn/P/ZSM-5 catalyst. ACS Catal. 5, 2982-2988 (2015)

17. Z. Bian, X. Meng, M. Tao, Y. Lv, Z. Xin, Effect of MoO3 on catalytic performance and stability of the SBA-16 supported Nicatalyst for CO methanation. Fuel 179, 193-201 (2016)

18. J.A. Cecilia, C. García-Sancho, J.M. Mérida-Robles, J. Santamaría-González, R. Moreno-Tost, P. Maireles-Torres, V and V-P containing Zr-SBA-15 catalysts for dehydration of glycerol to acrolein. Catal. Today 254, 43-52 (2015)

19. T. Torimoto, J.P. Reyes, S.-y. Murakami, B. Pal, B. Ohtani, Layer-by-layer accumulation of cadmium sulfide core: silica shell nanoparticles and size-selective photoetching to make adjustable void space between core and shell. J. Photochem. Photobiol. A 160, 69-76 (2003)

20. N. Liu, X. Zhu, S. Hua, D. Guo, H. Yue, B. Xue, Y. Li, A facile strategy for preparation of phosphorus modified HZSM-5 shapeselective catalysts and its performances in disproportionation of toluene. Catal. Commun. 77, 60-64 (2016)

21. X. Wu, A. Alkhawaldeh, R.G. Anthony, Investigation on acidity of zeolites bound with silica and alumina. Stud. Sur. Sci. Catal. 143, 217-225 (2002)

22. X. Liu, R.E. Truitt, DRFT-IR studies of the surface of $\gamma$-alumina. J. Am. Chem. Soc. 119, 9856-9860 (1997)

23. L. Wu, P.C.M.M. Magusin, V. Degirmenci, M. Li, S.M.T. Almutairi, X. Zhu, B. Mezari, E.J.M. Hensen, Acidic properties of nanolayered ZSM-5 zeolites. Micropor. Mesopor. Mater. 189, 144-157 (2014)

24. E.G. Derouane, J.C. Védrine, R.R. Pinto, P.M. Borges, L. Costa, M.A.N.D.A. Lemos, F. Lemos, F.R. Ribeiro, The acidity of zeolites: concepts, measurements and relation to catalysis: a review on experimental and theoretical methods for the study of zeolite acidity. Catal. Rev. 55, 454-515 (2013)

25. L. Zhao, H. Qin, R. Wu, H. Zou, Recent advances of mesoporous materials in sample preparation. J. Chromatogr. A 1228, 193204 (2012)

26. Y. Song, X. Zhu, Y. Song, Q. Wang, L. Xu, An effective method to enhance the stability on-stream of butene aromatization: posttreatment of ZSM-5 by alkali solution of sodium hydroxide. Appl. Catal. A 302, 69-77 (2006)

27. Y. Xin, P. Qi, X. Duan, H. Lin, Y. Yuan, Enhanced performance of $\mathrm{Zn}-\mathrm{Sn} / \mathrm{HZSM}-5$ catalyst for the conversion of methanol to aromatics. Catal. Lett. 143, 798-806 (2013) 